\title{
Mobilized to Take a Vanguard Role: Communist Party Members' Participation in the Community Building Campaign ${ }^{1}$
}

\author{
Ang $\mathrm{Yu}$ \\ Stanford University \\ angyu@stanford.edu / ang_yu@,outlook.com \\ Chengzuo Tang \\ The University of Chicago
}

(Last Modified: November 2017)

\begin{abstract}
In the community building campaign launched at the beginning of this century in urban China, the transfer of welfare responsibility to communities and democratization at the grassroots level both have featured prominently. Participation on the part of community residents as volunteers and voters are indispensable to the success of these initiatives. Therefore, grassroots state agents are eager to solicit involvement from those susceptible to their mobilization, including Communist Party members. In this article, we intend to investigate the role of Party members in community volunteering and voting and its differentiation across various social groups and neighborhood contexts. Drawing on nationally representative data, we find that Party members indeed have a stronger propensity to participate than the nonmember residents. The effect of Party membership is statistically significant on volunteering but not on voting, and more distinguishable among employed than retired residents. In danwei neighborhoods, the direction of Party membership's influence is reversed. These findings shed some light on the targets, emphasis, channels and constraints of Party-state's grassroots mobilization in its quest of maintaining legitimacy in a cost-effective way.
\end{abstract}

Keywords: community building, party membership, social participation, neighborhood context

\section{Introduction}

Since the initiation of the community building campaign at the turn of the $21^{\text {st }}$ century, communities have been increasingly vital sites in both the municipal governance structure and everyday life of Chinese urbanites. Concerned with various topics, studies examining determinants of urban residents' community participation have proliferated. Some of those studies have provided the overall pictures at the national level, with attention directed to the effects of residents' home-ownership, hukou, and social capital on voting at the community

${ }^{1}$ We would like to thank Xiaogang Wu, Andrew Walder, Lisa Hoffman and participants in the 2017 Urban China Research Network (UCRN) Conference and the 5th Young Scholars' Conference on China Studies at HKBU for helpful comments on previous versions of this article. 
level(J. Li and Wang 2012; J. Li 2009; Z. Chen, Lu, and Xu 2015; Wang 2016; Q. Xu, Perkins, and Chow 2010). However, the impact of residents' political status on their community participation has been left understudied, especially when it comes to other forms of participation aside from voting. Given the salience of state in the Chinese urban communities, the participatory role played by Chinese Communist Party(CCP) members who are the embodiment of Party-state's apparatuses certainly deserves attention. Without considering how Party members act in it, a comprehensive understanding of how community building campaign is implemented cannot be attained. Therefore, we will use nationally representative data to explore whether CCP affiliation has an impact on residents' community participation and the ways in which the potential impact is formulated and differentiated. In terms of the forms of participation, we will particularly examine voting in elections of Residents Committees(RCs) and volunteering in communities. These two participatory activities are not only attached with great importance in the community building campaign but also readily accessible to ordinary residents at any time and places, thus rendering pooling geographically dispersed communities into one sample plausible.

This article is inspired by another line of inquiry as well, namely the social implications of being a Party member in China. The membership of Chinese Communist Party (CCP) has been found to be a strong facilitator of life chances, in terms of career mobility(Walder, Li, and Treiman 2000; B. Li and Walder 2001; Walder 1995), income(Appleton et al. 2009), housing acquisition(Pan 2004; Walder and He 2014), and entrepreneurial benefits(Li et al. 2008). Generally, party members fare better than others, but knowing that they get more leads us to wonder whether they give more too. However, the behavioral implications other than personal and material gains of the communist party membership received relatively less attention. A handful of studies have found that Party members tend to participate more actively in various forms of political activities(Guo 2007; Shi 1997, 164-79) despite that the opposite evidence is discovered for the anti-Japanese demonstration in Beijing(Zhou and Wang 2016). Especially, Dickson(2014) has found that in order to demonstrate their mobilized loyalty, Party members are more likely to engage in civic as well as political activities. But these studies do not address forms of participation rooted in communities. Participation in different social venues may differ from one another qualitatively, and the most daily and quotidian life of Party members in their residential areas merits specific attention. In the political screening process of Party member recruitment, applicants' participation in voluntary activities and community service is said to serve as a way to declare loyalty(Bian, Shu, and Logan 2001, 814), but it is merely an anecdotal observation. Even if it is true nationwide, we still do not know whether Party members would continue to do so after they already obtained the Party membership.

Party members are constantly placed under a heightened obligation to play a 'vanguard' role in leading the society at large, but is this ideological mandate translated into actual actions of the members? Considering the fact that in the post-reform era the Party only wield very limited control over the distribution of material benefits and career prospects in many social arenas, the mobilization capacity of the Party may be reasonably questioned. Finally, if they are indeed more likely to participate, what is the pattern of their participation relative to the others'? We intend to answer these questions by looking into Party members' engagement in 
within-community activities that are advocated in the community building campaign by the Party-state.

\section{Background and Hypotheses}

\section{Community building campaign and CCP members' community participation}

The community building campaign is continuously shaping the social landscape of urban China and serving as the backdrop against which the community dynamics are unfolding. At the turn of the $21^{\text {st }}$ century, the drastic economic and administrative reforms entailed several transformative dynamics, rendering the consolidation of urban communities a necessity for China's Party-state. First, the previously predominant danwei system was dismantled, the stateowned-enterprises and public institutions withdrew themselves from service delivery and social control, thus leaving a void to be filled. Second, housing commercialization severed the previous link between workplace and residence, thus generating a whole new class of homeowners whose residential matters falling outside of the direct reach of state. Third, the social security and management system was challenged and destabilized by a more vulnerable, diversified and fluid population residing in cities, including the unemployed, the elderly and the immigrant workers flowing from rural areas. Fourth, under the pressure of enhancing efficiency, streamlining administration and downsizing functions, the municipal governments were eager to delegate their responsibilities to local organizations and societal actors. In order to tackle with these transitions which, if left unattended, would threaten the grassroots stability and legitimacy of Party-state and to fulfill the new expectations imposed on municipal governance, urban communities were assigned by the policy makers at central level to come to the fore. In other words, in the efforts of Party-state to secure its legitimacy and infrastructural powers over urban grassroots society, the communities are strengthened in its functions of surveillance, liaison, mediation, environmental maintenance, service delivery and welfare provision(Y. Xu 2008; Benewick and Takahara 2002; Heberer and Göbel 2011; Derleth and Koldyk 2004). Therefore, after the Opinions on Extending and Furthering Urban Community Construction was released by the Ministry of Civil Affairs(2000), the grand project of community building was set in motion nationwide.

To satisfactorily perform its newly-endowed critical responsibility in urban governance, RCs cannot solely depend on their own staff since the onerous workloads demand more labor force than the local governments are able or willing to afford(Derleth and Koldyk 2004; A. Yang and Yu 2012; Bray 2006, 539-41). Ordinary residents are requested to solve the problems in their own community through voluntary involvement and self-service. In various forms, the community dwellers are recruited by the RCs to become volunteers, assisting RC staff in gathering fees and information, maintaining social order, providing care and services to welfare recipients, cleaning and beautifying the neighborhood, and other miscellaneous affairs(Read 2012, 184-90). In doing so, community volunteers become partners of Party-state, serving its local needs of governing and overall concerns of stability and legitimacy(Luova 2011).

As is shown in Figure 1, the community building campaign accompanies the downsizing of the formal structure of RCs and the rising importance of voluntary participation of residents. Despite that urban areas and governing undertakings have been expanding rapidly in last two 
decades, the number of RC members declined by above $20 \%$ from 1998 to 2002 and did not return to the level in 1998 until 2015. Meanwhile, the number of community volunteers in urban China has increased from 3682 thousand in 1999 to 5076 thousand in 2010 and still been 'constantly increasing' in recent years (Ministry of Civil Affairs of PRC 2016a).

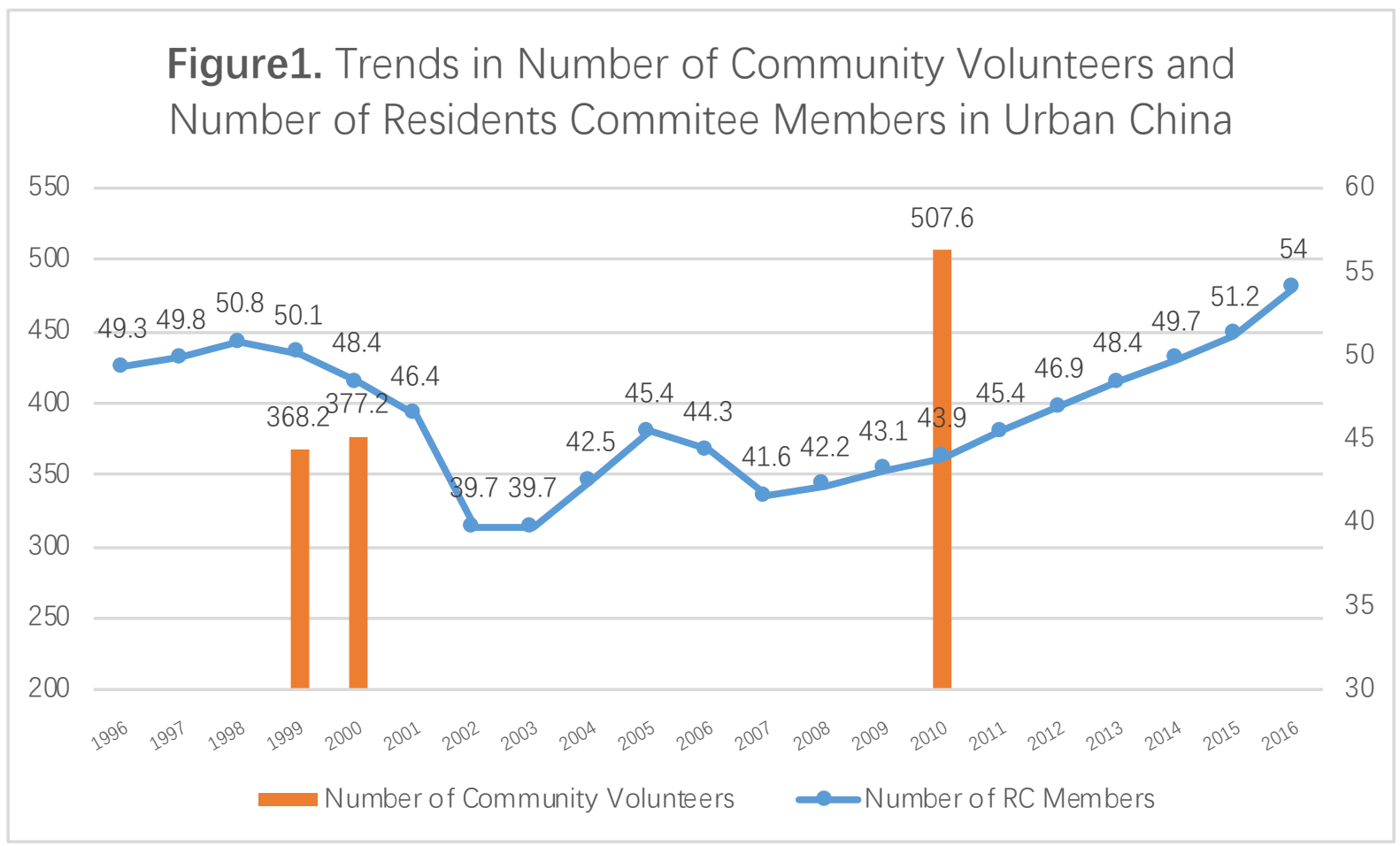

Data sources: Ministry of Civil Affairs of PRC (2016b); Office of the State Council(2011)

This practice of decentralization of responsibilities to urban communities and responsibilization of social actors acting as volunteers(Hoffman 2013) is but one side of a broad transformation of governing in urban China. Under the banner of self-governance as a new governing mentality and mode proposed by Party-state, the administrative and service burdens shouldered by RCs and volunteers are matched with the grassroots democratization, which is mainly embodied by the election of RC members. Although the RCs have been lawfully stipulated to be elected by residents for decades, the democratization at the community level didn't gain substantial momentum until the start of community building campaign at the end of the 1990s. Since then, the communities are viewed by scholars and officials alike as a vital locus of democratization and importance has been attached to the participation in RC election by qualified citizens. However, some argued that the RC elections only serve to regularly refresh the composition of RC members to local state's favor in a seemingly legitimate manner. This interpretation is consistent with a common observation that the RC elections are still not fair, free and genuine(Read 2012, 73-78). One way or another, the local agents of Party-state have been dutifully organizing each round of elections under administrative commands, sometimes they even get over-zealous to their job, as indicated in the direct election initiative in Shanghai(see Xiong 2008). 
It is evident that the two major components of community building campaign both demand active participation of rank and file residents. Without the dedicated involvement of residents serving as volunteers, the tasks assigned to communities cannot be accomplished; without residents' participation as voters, the democratization goals set by administrative organs also would be impossible to be met. Put in another way, the Party-state's needs are vested in the community building campaign whose success is decisively determined by whether citizens actively participate in volunteering and voting within their residential communities. Yet the ends advocated by state are not automatically and smoothly served by the residents, as the increased residential mobility are corrosive of the community cohesion thus thwarting volunteerism and the lack of bona fide elections impairs residents' collective efficacy hence preventing them from voluntarily turning up in the $\mathrm{RC}$ elections. In addition, in stark contrast to what is going on in rural China, the composition of RCs, their performance in implementing state's projects along with their decision-making process are virtually irrelevant to the vast majority of residents' interests(Ho 2010, 209-13, 221; Derleth and Koldyk 2004). Consequently, the residents generally do not have the incentive to concern themselves with community affairs.

Therefore, the grassroots policy implementers are faced with the question that whom are to be enlisted as participants from a constituency that is largely apathetic to their communities. Abundant evidence has shown that CCP members are among the social groups particularly targeted by the RCs and Street Offices. In fact, CCP members act as an indispensable 'reservoir' of the labor force for mobilized community participation(Takahara and Benewick 2006; Heberer and Göbel 2011, 97). For the instance of the RC direct-election in Shanghai, CCP members and other activists are linchpins of the mobilization work of the election organization committees with the purpose of achieving the turnout rate target set by Street Offices(Y. Gui, Cheng, and Ma 2006; Xiong 2008). Just like the Party-state regime relies upon rank and file Party members as its social base in general(Walder 2004), it appears to rely upon the latter's enduring allegiance in the particular case of community building.

The active participation of CCP members may have something to do with two characters of them, namely their organizational bonds with Party organizations and their psychological susceptibility to be mobilized by the Party organizations. In other words, these are the two mechanisms assumed to make Party members more likely to participate than their non-member neighbors. To begin with, the organizational bonds between individual Party members and the Party-state as a whole take effects against the backdrop that the territorial administration and CCP organizations at the base level are simultaneously reinforced. The strengthened grassroots party organizations take shape as the community PPOs (primary party organizations) that are not only juxtaposed with but also merged with RCs(Yong Gui, Ma, and Mühlhahn 2009, 409). The community PPOs are assigned with a vital position in urban grassroots governance to territorially coordinate the party building in both state and non-state sectors(Zhang 2015), and to take on leadership or guidance role in community building campaign(Takahara and Benewick 2006). In an 'opinion' issued by General Offices of the CPC Central Committee and the State Council, it is explicitly urged that 'members of community PPOs and RCs take office intersectantly...community PPOs strengthen the leadership and direction of the community 
committee election work...community Party Building be closely tied to harmonious community construction...further implement the requirement of making employed Party members register in communities, broaden Party members' channels of serving the masses, give full play to the vanguard-model role played by Party members in the harmonious community building (General Office of the CPC Central Committee and General Office of the State Council, 2010).

Furthermore, due to the sense of obligation bound with Party membership which is attained by virtue of screened political commitment(Bian, Shu, and Logan 2001; D. Li and Tang 2016), CCP members are generally prone to align themselves with the objectives pursued by the regime. Given that community engagement demands only minor amount of efforts and time, even a limited level of identification with the state's wishes on the part of Party members can exert a discernible effect. For example, Zhang(2017) found that some of the part-time Party workers are incentivized by their identity with the Party and its ideology to serve the Party in the non-public sector in urban China. Also, those with more receptivity or less independentmindedness are more likely to be recruited into the rank of Party(Xie and Zhang 2016), making soliciting Party members to participate more easily. These two mechanisms most likely operate in a combined way. That is to say, the organizational bond is the means through which the psychological susceptibility of Party members is materialized into actual participatory actions on the ground.

Based on the existent evidence and the two supposed mechanisms through which the Party members are get involved, we propose the first hypothesis:

Hypothesis 1: CCP members are more likely to participate in their communities, both in terms of volunteering and voting.

Besides, the Party-state might be more obsessed with boosting its output or performance legitimacy by recruiting volunteers to strengthen welfare provision, improve environment and preserve stability than with mobilizing voters to increase the turnout rate of RC elections. Therefore, a partially competing hypothesis is constructed:

Hypothesis 1A: CCP members more likely to participate in their communities only in terms of volunteering, but not in terms of voting.

\section{Employment status and the varied effects of CCP membership}

How party members act in the communities can be better understood in light of the differentiation of the membership effect across theoretically important social categories. In this and the following sections, we will discuss the potential variegation in the effects exerted by CCP membership, if there is any, along the lines of employment status and neighborhood types. Regarding employment status, there are two scenarios which are both conceivable but contradict each other, hence two sets of competing hypotheses arise. We will address them separately.

On the one hand, the aforementioned organizational mechanism is supposed to have a larger impact on retired Party members than on their currently employed counterparts. The 'organizational relations' of Party members are transferred to the Party organizations of their residential area upon their retirement, making them directly under the jurisdiction of the 
community PPOs thereafter. As Yang $(2007,147)$ observed, retired Party members one of the 'major subjects' of community participation in urban China.

So, a hypothesis about the interacting effects of employment status and Party membership is formulated as such:

Hypothesis 2: As for increasing the likelihood of community participation, Party membership yields a stronger effect among retired members than among currently employed members.

On the other hand, the generally higher rate of participation among retired residents in community affairs may have a levelling effect to attenuate the impacts of Party membership. Not uniquely in China, as retirees retreat from their previous workplaces, they tend to seek senses of belonging, meaningfulness, collectiveness, and sociability through taking part in voluntary activities along with their neighbors(Okun and Schultz 2003; Heberer and Göbel 2011, 126). As RCs' mobilization work is often based on the daily interaction between RC staff, by extension, community activists who revolve around the former, and the ordinary residents (Y. Gui, Cheng, and Ma 2006; Xiong 2008), the grassroots mobilizers can easily take advantage of their rapport with the retired elderlies which is established due to the increased frequency of activities of the retirees in the communities. As a result, the general proclivity of retirees to commit themselves to community affairs may make the Party members' privileged status of mobilization target no longer hold. Conversely, it is the general apathy of working residents that makes Party membership distinctively salient. Accordingly, hypothesis $2 \mathrm{~B}$ is proposed as a competing alternative to hypothesis $2 \mathrm{~A}$.

Hypothesis 2A: As for increasing the likelihood of community participation, Party membership has a more distinctive effect among currently employed residents than among retired residents.

\section{Danwei compounds and the reversed direction of influence}

Qualitative and quantitative studies have agreed on the starkly diverging ecologies of different types of residential neighborhoods in urban China and their imprint on residents' grassroots participation(Tomba 2014; Hsing 2012; Forrest and Yip 2007; J. Li and Wang 2012). Therefore, we will investigate whether the relation between Party membership and community participation varies across different neighborhood types. Especially, we are interested in shedding light on how this relation plays out in Danwei compounds, as it is considered indicative of the transition of Chinese urban governance regime.

Danwei compounds refer to those housing complexes built by the danweis that consist of state-owned enterprises, the public institutions, and governmental organizations. They are legacies of the housing allocation system in the pre-reform era which distributes apartments to danwei employees as items of social welfare, charging only minimal rents. Danwei compounds were constructed to be self-contained living neighborhoods, exclusively accommodating employees of the same danwei, so that working and residential lives of danwei employees are closely wedded(Bray 2005, 141-44). There is still a large proportion of urban land occupied by danwei compounds built before or during the housing commercialization reform that is gradually progressing and still ongoing now. Although housing and community governance reforms have substantially diminished the link between danwei employers and the housing 
compounds, in danwei compounds, the relatively high degree of residential concentration of residents working in the same danwei continues to make their shared employer a considerable factor influencing residents' community participation.

In terms of community volunteering, Danweis preserve their function of mobilizing outwardly civic activities such as philanthropic donations on the part of their employees(Bi et al. 2010; Erwin, Adams, and Le 2009), hence supposedly distract the civic interests and spare time of danwei employers from being invested in voluntary services in communities. If it is true that Party members working in danweis are more pressurized to participate in danweisponsored civic activities than their non-member colleagues, then Party membership will have a negative effect on community volunteering among residents of danwei compounds.

In terms of community voting, the danwei context may also yield a distraction or even squeezing effect such that Party membership will be negatively associated with voting in community elections. As $\mathrm{Hu}(2008,156)$ pointed out, seeking support from danwei leaders remains an important means of problem solving and form of political participation(see Shi 1997, 46-51). It can be surmised that relative to non-member coworkers in danweis, Party members are better able to convert their political status into advantages in danwei-based channels of interest articulation. Consequently, Party members living in danwei compounds that have a higher density of danwei employees would prefer articulating interests through danwei-based channels over voting for RC members, when needs arise. The proposition argued above can be summarized as a reversed direction of Party membership's influence in Danwei compounds, if an overall positive impact of Party membership on community participation can be identified in the first place. This leads us to hypothesis 3:

Hypothesis 3: In the subsample of danwei compounds, Party members are less likely to participate in community volunteering and voting.

The separate analyses across different types of neighborhoods should not be confined to danwei compounds. However, due to the lack of theoretical or fieldwork studies that lay a sound foundation for hypotheses construction, we tend to conduct the analyses within subsamples of neighborhood types other than the danwei compound in a tentative manner and refrain from proposing hypotheses at this point.

\section{Data, variables, and methods \\ Data}

The analysis in this article is based on the data of CGSS2012. The Chinese General Social Survey (CGSS) is a nationwide, repeated, cross-sectional general survey project in China and We choose CGSS2012 because it is the most up-to-date round with available information on volunteering and voting within urban communities. In addition, this round of CGSS uniquely contains measures related to social capital, thus making possible controlling for social capital in the context of community. CGSS2012 adopted a multistage stratified sampling design to obtain nationally representative samples of Chinese adults age 18 or above, collecting data from all provincial-level administrative regions except two, Tibet and Hainan. In all regression models, we use the built-in weight variable to correct for the differential weights of 
observations caused by the sample design, and statistical inferences are based on robust standard errors.

To acquire an administratively homogenous sample with regards to the governance structure that is critical to community participation, we restrict the analysis to 'urban' sample by a rather strict standard. Firstly, the cases whose residential areas are recorded as villages or townships (as opposed to counties and municipalities) are excluded. Secondly, the cases whose grassroots governing institutions are either villagers' committee (at the lowest rung) or township government (at the second lowest rung and as opposed to Street Office) are also dropped from the analytic sample. 15 cases residing in welfare housing neighborhoods are also dropped since they unitarily do not participate in community volunteering hence rendering binary choice models automatically exclude them. At last, Cases with missing values on any variables constitute $15.65 \%$ of the full sample, they are excluded from analysis as well. After these procedures, there are 1817 respondents in the analytic sample.

\section{Dependent and independent variables}

Volunteering is a dummy variable combining information from two items in the questionnaire. On the one hand, Respondents who answered 'yes' to the following question: "In the past 12 months, have you participated in activities related to the public interest? volunteering activities for building your own community" are coded as 1 and 0 otherwise. On the other hand, respondents are also asked about whether they have "personally participated in social volunteering service activities", and those answering "yes" were asked an ensuing question: "How many hours did you spend on participating in each category? - neighborhood and community service". Anyone who was asked this ensuing question and responds a positive value to it is also coded as 1 .

Voting is a dummy variable indicating whether the respondent cast vote in the last election of community RC, with voters coded as 1 and non-voters as 0 .

The core independent variable is Party, which is coded as 1 if the respondent is a member of CCP and as 0 if not. About $16.8 \%$ respondents in the analytic sample are CCP members.

\section{Control Variables}

Three demographic factors are controlled for, including sex $(0=$ female, $1=$ male $)$, age, agesqr, and marital status $(0=$ unmarried, $1=$ married $)$. Because Party membership is associated with getting ahead in the socio-economic order of contemporary China, four factors related to socioeconomic status are also accounted for. Lincome is the logarithm of yearly income of the respondent in 2011, and the 0 values are recoded into 1 before logarithm transformation. Hukou is coded as 1 if the respondents' hukou is registered in the 'street' (jiedao, the jurisdiction of a Street Office) where he or she is currently dwelling and 0 if hukou registered outside the street. Education is coded as a categorical variable ( $0=$ primary or below, 1 = junior, 2 = senior, 3 = college or above). Homeownership is a long-established predictor of community participation in democracies (Mccabe 2013), domestic Chinese scholars also have found that homeowners in commercial estate neighborhoods tend to be actively involved in RC elections (Guan and Cai 2015; J. Li and Wang 2012). Homeownership is included as a trichotomies variable to capture the multidimensional nature of property rights(Zavisca and Gerber 2016) $(0=$ renters, $1=$ owned by relatives, $2=$ owned by the respondent or spouse). 
Type of community is included in the full-sample models as a categorical variable $(0=$ unredeveloped old neighborhoods, $1=$ danwei compounds, 2 = ordinary commercial estate, $3=$ villas or high-end neighborhoods, $4=$ newly converted urban village). Note that the jurisdiction of an RC usually encompasses several neighborhoods (xiaoqu) which are sometimes but not always varying in terms of these types.

Employment is a discrete variable containing three categories $(0=$ employed, $1=$ unemployed, 2 = retired). For the purpose of testing hypotheses, my focus is on the contrast between employed and retired residents.

Embeddedness is a scale constructed by adding three standardized items which respectively measure the respondent's frequency of socializing with neighbors in recreational activities, the number of neighbors the respondent would say hello to and the number of neighbors from which the respondent can seek help. The items directly measure the respondents' intensity of interaction with neighbors, which in turn shows his or her embeddedness in the horizontal social network within the community. Embeddedness produces an internal consistency reliability (Cronbach's alpha) of 0.62 .

Neighborliness denotes the degree to which the respondent perceives his own community to be a neighborly and cohesive one. This scale combines four standardized items, including trustworthiness of the neighbors, the willingness of neighbors to offer help, the mutual caring among neighbors and the prospect of neighbors to unite when a natural disaster occurs, all as perceived by the respondent. The Cronbach's alpha of Neighborliness is 0.72 .

Embeddedness and neighborliness can be deemed as private social capital at the personal level and collective social capital at the community level respectively (Portes 2000). When analyzing other determinants of community voting in urban China, a few studies have taken party membership as a control variable and reported its positive effects with statistical significance(J. Li and Wang 2012; Wang 2016). However, due to the deficiency of measurements, all studies based on nationally representative data failed to control for factors related to social capital in their models, whilst these factors are actually found to be strong predictors of community participation in urban China(Zhu and Fu 2016; J. Chen and Lu 2007). Note that the social capitals referred to are those produced and maintained within the boundaries of residents' own communities, as Xu et al.(2010) reported that the overall private social capital is a less significant predictor of local political participation relative to factors that fall into the categories of embeddedness and neighborliness in this study. By the incorporation of the two social capital variables, we may test whether the significantly positive effect of Party membership persist after the two social capital variables are held constant.

\section{Analytical strategy}

To examine the hypothesis 1 and 1A, a set of nested logit regressions are at first estimated in the full analytic sample. At the first step, the models predicting the two kinds of participation by CCP membership, only controlling for demographic variables, employment status and community type. At the second step, control variables related to socio-economic status are added, including Lincome, Hukou, Education and Homeownership. At the final step, all control variables, including the two related to social capital are incorporated in the model. 
Then two logit models are estimated to determine which of the competing hypotheses 2 and $2 \mathrm{~A}$ is warranted by data. In these two models, the interaction terms between Party membership and employment status are included in addition to all the control variables.

Finally, in order to explore the effects of party membership in different neighborhood ecologies and examine hypothesis 3, we apply logit models within three types of neighborhoods which have sufficiently large sample sizes, i.e. un-redeveloped old neighborhoods, danwei compounds and ordinary commercial estates. By dividing the full sample into subsamples, we allow for a full interaction between community types and independent variables of interest. The coefficients of all models are adjusted according to weighting design of the survey and the significance levels are calculated based on robust variance.

\section{Results}

Table 1. Mean and percentage by party membership, Urban China in 2012

\begin{tabular}{lllll}
\hline Variables & Total & Nonmembers & Members & Difference test \\
\hline Volunteering (\%) & 11.67 & 10.05 & 19.67 & $\mathrm{t}=-4.80^{* * *}$ \\
Voting (\%) & 37.64 & 35.38 & 48.85 & $\mathrm{t}=-4.45^{* * *}$ \\
Sex (\%) (male=1) & 50.14 & 46.63 & 67.54 & $\mathrm{t}=-6.74 * * *$ \\
Age & 48.43 & 47.08 & 55.12 & $\mathrm{t}=-7.71 * * *$ \\
Marital (\%) (married=1) & 75.07 & 72.69 & 86.89 & $\mathrm{t}=-5.27 * * *$ \\
Lincome & 9.46 & 9.28 & 10.32 & $\mathrm{t}=-6.57 * * *$ \\
Employment (\%) & & & & $\chi 2=24.37 * * *$ \\
Employed & 55.21 & 56.17 & 50.49 & \\
Unemployed & 15.94 & 18.50 & 3.28 & \\
Retired & 28.85 & 25.33 & 46.23 & \\
Hukou (\%) & 65.00 & 63.49 & 72.46 & $\mathrm{t}=-3.00^{* *}$ \\
Education (\%) & & & & $\chi 2=99.84 * * *$ \\
Primary or below & 15.85 & 17.26 & 8.85 & \\
Junior & 25.70 & 28.57 & 11.48 & \\
Senior & 28.89 & 29.03 & 28.20 & \\
College or above & 29.55 & 25.13 & 51.48 & \\
Homeownership (\%) & & & & $\chi 2=33.10^{* * *}$ \\
Renters & 20.86 & 22.42 & 13.11 & \\
Owned by relatives & 23.89 & 25.33 & 16.72 & \\
Owned by the respondent or spouse & 55.26 & 52.25 & 70.16 & \\
Type of community (\%) & & & & \\
Un-redeveloped old neighborhoods & 25.48 & 27.45 & 15.74 & \\
Danwei compounds & 17.01 & 16.93 & 17.38 & \\
Ordinary commercial estate & 47.94 & 46.16 & 56.72 & \\
Villas or high-end neighborhoods & 2.04 & 1.72 & 3.61 & \\
Newly converted urban village & 7.54 & 7.74 & 6.56 & \\
& & & & \\
& & & \\
\end{tabular}




\begin{tabular}{lllll} 
Embeddedness & 0.03 & 0.00 & 0.15 & $\mathrm{t}=-2.93 * *$ \\
Neighborliness & 0.01 & 0.00 & 0.07 & $\mathrm{t}=-1.43$ \\
$\mathrm{~N}$ & 1817 & 1512 & 305 & \\
\hline
\end{tabular}

Note: $* \mathrm{p}<0.05 ; * * \mathrm{p}<0.01 ; * * * \mathrm{p}<0.001$ (two-tailed tests).

Means and percentages of each variable by party membership are presented in Table 1, the difference tests for each variable almost uniformly point out significant divergences between party members and non-party members. Therefore, although party members do appear to have higher rates of participation in community volunteering and voting, multivariate modelling are needed before we can confirm the relationship is not spurious.

Table 2. Coefficients of Logistic Models, Urban China in 2012 ( $\mathrm{N}=1817)$

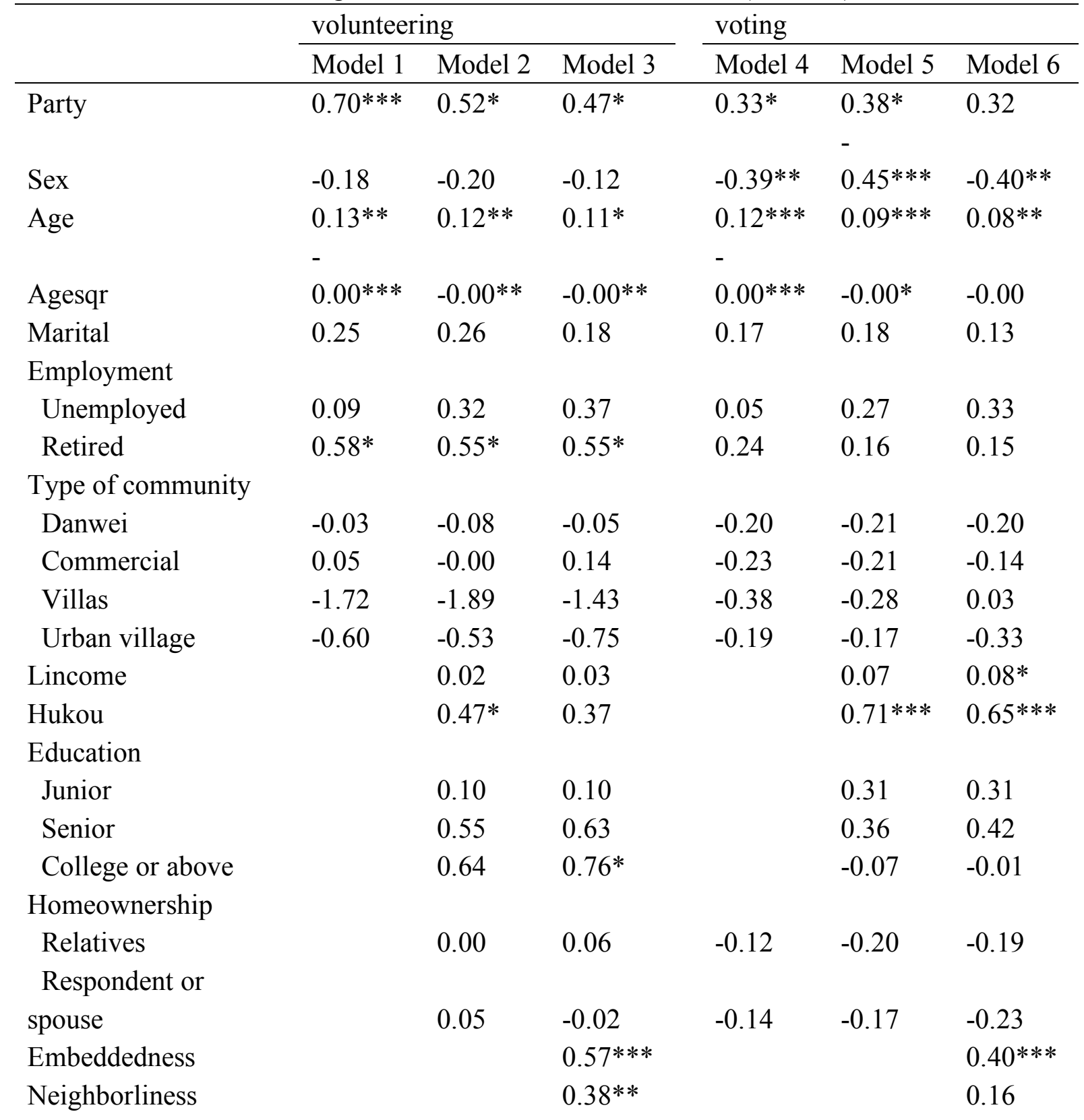


Constant

Notes: $* * * \mathrm{p}<0.001 ; * * \mathrm{p}<0.01 ; * \mathrm{p}<0.05$. As for homeownership, relatives and respondent or spouse stand for owned by relatives and owned by respondent or spouses respectively. As for types of community, danwei, commercial, villas and urban village stand for danwei compounds, ordinary commercial estate, villas or high-end neighborhoods, newly converted urban village respectively.

As a starting point, Table 2 contains the logit models in full sample without interaction terms. In model 1 and model 4 as the baseline, the effects of Party membership on both volunteering and voting are significantly positive. The inclusion of socio-economic variables in Model 2 and Model 5 alter the logit coefficient, but the effects remain statistical significant. Model 3 and model 6 show that the incorporation of social capital factors leads to attenuation of effects of Party membership on both kinds of participation and the cessation of statistical significance in the case of voting. This finding justifies the special attention given to the role of control variables related to social capital and implies that the previous studies (J. Li and Wang 2012; Wang 2016) might have found an overestimated correlation between Party membership and community voting because of the failure to take social embeddedness into consideration. But the influence of Party membership nevertheless remains substantial even after social capitals are held constant. For Party members, the odds of participating in the community are approximately $60 \%$ higher in volunteering and $37 \%$ higher in voting than nonParty members, ceteris paribus. The logit models in Table 2 indicate that statistical significance only applies to Party membership's effect on volunteering but not to its effect on voting, so some supports are lent to hypothesis $1 \mathrm{~A}$ that $\mathrm{CCP}$ members more likely to participate in their communities only in terms of volunteering, but not in terms of voting. The implication is that CCP's vigor in mobilizing its members to get involved in the community building campaign is definite while the Party-state is perhaps more concerned with boosting output legitimacy and social stability than mobilizing voters to increase the turnout rate of RC elections.

Though it might be the case that people with more intrinsic propensity to participate are more likely to self-select into the party, to the best knowledge of the authors, there is no evidence for this proposition. Therefore, we do not expect the party members are internally more motivated to dedicate themselves to community activities than non-members. Even if endogeneity induced by self-selection does exist to some degree, it is highly unlikely that the positive correlation is entirely driven by endogeneity. The mechanism of organizational bonds translating Party members' psychological susceptibility into actual actions is backed by ample previous research. Hence, without the organizational presence of community PPOs and the mobilization works done by them, Party members should not engage themselves as intensively as is found now.

In addition, the retirees are significantly more inclined to become community volunteers. Though they also have a stronger inclination to vote, the coefficient is not significant. Female residents appear to be significantly less likely to vote in RC elections while people with local 
hukou are more likely to do so. Residents who have completed college education have stronger propensity to act as community volunteers but have equal propensity to vote as others. Higher income also lead to higher likelihood to be a voter. Of particular interest is the significantly positive relationship between embeddedness and the two forms of participation which reaffirms the conventional perception that the urban community in China have a Janus face, simultaneously being a social complexity in which embeddedness facilitates the enthusiasm for getting involved and a governance unit in which the agents of state perform mobilization works.

Table 3. Coefficients of Logit Models with Interaction Terms $(\mathrm{N}=1817)$

\begin{tabular}{|c|c|c|}
\hline Party & $0.88 * *$ & $0.67 * *$ \\
\hline Sex & -0.10 & $-0.39 * *$ \\
\hline Age & $0.09 *$ & $0.07 * *$ \\
\hline Agesqr & $-0.00 *$ & -0.00 \\
\hline Marital & 0.20 & 0.14 \\
\hline \multicolumn{3}{|l|}{ Employment } \\
\hline Unemployed & 0.51 & 0.38 \\
\hline Retired & $0.79 * *$ & 0.30 \\
\hline \multicolumn{3}{|l|}{ Type of community } \\
\hline Danwei & -0.05 & -0.19 \\
\hline Commercial & 0.13 & -0.15 \\
\hline Villas & -1.38 & 0.08 \\
\hline Urban village & -0.70 & -0.34 \\
\hline Lincome & 0.03 & $0.08 *$ \\
\hline Hukou & 0.36 & $0.64 * * *$ \\
\hline \multicolumn{3}{|l|}{ Education } \\
\hline Junior & 0.12 & 0.33 \\
\hline Senior & 0.68 & $0.45^{*}$ \\
\hline College or above & $0.77 *$ & -0.01 \\
\hline \multicolumn{3}{|l|}{ Homeownership } \\
\hline Relatives & 0.05 & -0.19 \\
\hline Respondent or spouse & -0.04 & -0.24 \\
\hline Embeddedness & $0.57 * * *$ & $0.40 * * *$ \\
\hline Neighborliness & $0.37 * *$ & 0.16 \\
\hline \multicolumn{3}{|l|}{ Party*Employment } \\
\hline Party*Unemployed & -1.64 & -0.20 \\
\hline Party*Retired & $-0.84 *$ & $-0.70^{*}$ \\
\hline Constant & $-5.72 * * *$ & $-4.31 * * *$ \\
\hline $\mathrm{AIC}$ & 1272.40 & 2266.95 \\
\hline
\end{tabular}

Notes: $* * * \mathrm{p}<0.001 ; * * \mathrm{p}<0.01 ; * \mathrm{p}<0.05$. As for homeownership, relatives and respondent or spouse stand for owned by relatives and owned by respondent or spouses respectively. As for types of community, danwei, commercial, villas and 
urban village stand for danwei compounds, ordinary commercial estate, villas or high-end neighborhoods, newly converted urban village respectively.

Table 3 shows the logit models with interaction terms. It is found that the interaction terms between Party membership and retirement status have significantly negative signs in both the models for volunteering and voting participation. This pattern is consistent with the hypothesis 2A which postulates that Party membership yields a stronger effect among currently employed than among retired residents. The attenuating or levelling effects of retirement and embeddedness on the link between Party membership and community participation are confirmed. This levelling effects can be attributed to such a process: the grassroots mobilizers deem retirees and Party members alike as similarly reachable and susceptible to mobilization, thus making these two targets groups interchangeable and complimentary to each other, consequently making the distinctiveness of Party members disappear among the retired. This process is illustrated by Figure 2. The differences in predicted probabilities of community participation of employed Party members and non-members are obvious, but when the residents retire, they are generally active in participation and the difference caused by Party membership no longer discernable.

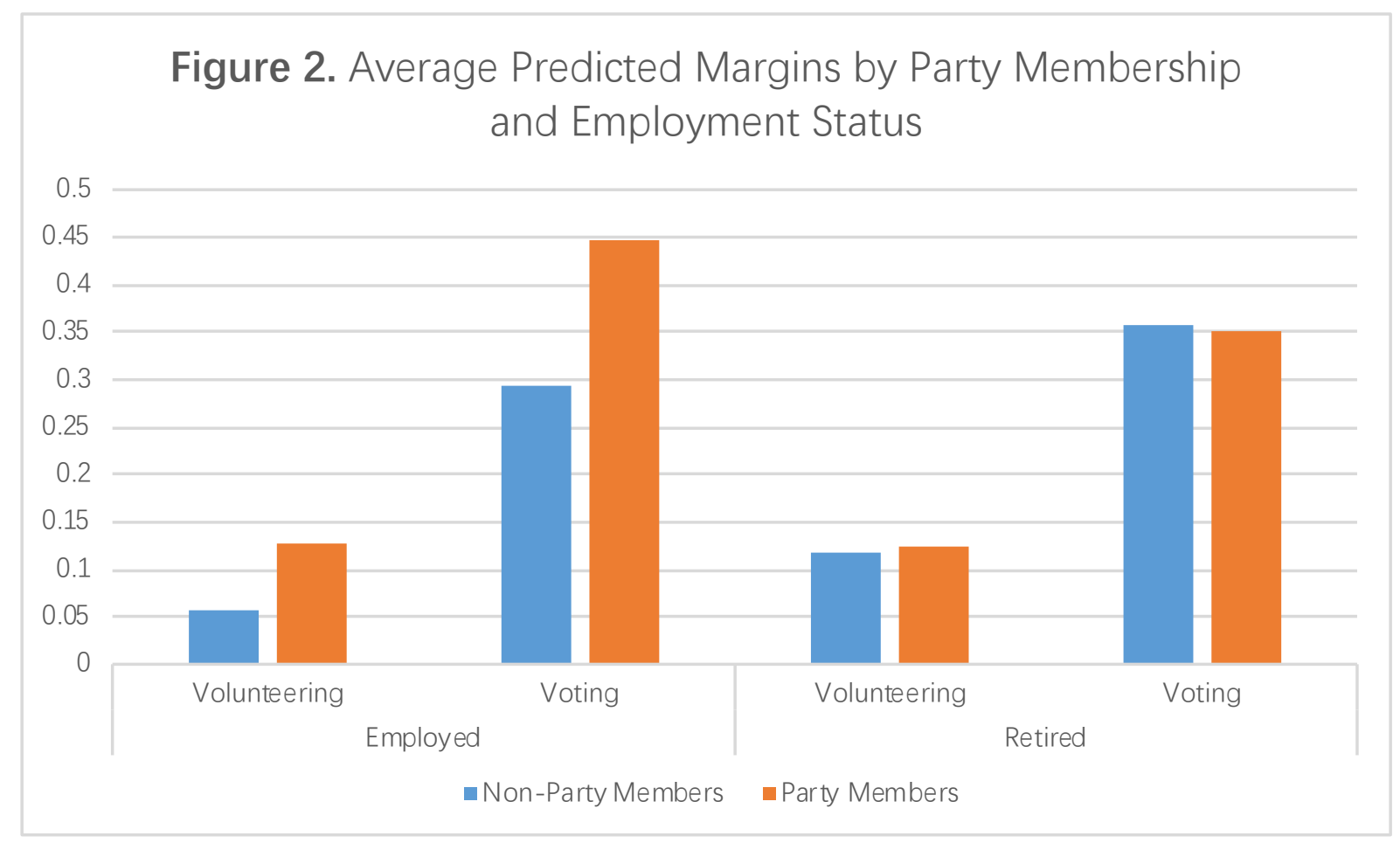

Table 4. Coefficients of Logit Models by Type of Neighborhood, Urban China in 2012

\begin{tabular}{lllllll}
\hline & \multicolumn{2}{l}{ Old un-redeveloped } & \multicolumn{2}{l}{ Danwei compounds } & \multicolumn{2}{l}{ Commercial estate } \\
& volunteering & voting & volunteering & voting & volunteering & voting \\
& Model 1 & Model 2 & Model 3 & Model 4 & Model 5 & Model 6 \\
\hline Party & $1.11^{*}$ & 0.18 & -0.12 & -0.65 & $0.55^{*}$ & $0.45^{*}$ \\
Sex & -0.46 & $-0.46^{*}$ & 0.20 & 0.11 & -0.18 & $-0.45^{*}$
\end{tabular}




\begin{tabular}{|c|c|c|c|c|c|c|}
\hline Age & 0.13 & $0.10^{*}$ & 0.08 & 0.10 & 0.10 & $0.09 *$ \\
\hline Agesqr & -0.00 & -0.00 & -0.00 & -0.00 & -0.00 & -0.00 \\
\hline Marital & -0.71 & -0.22 & 0.66 & 0.04 & 0.23 & 0.34 \\
\hline \multicolumn{7}{|l|}{ Employment } \\
\hline Unemployed & -0.93 & -0.27 & 0.18 & 1.09 & -0.12 & -0.13 \\
\hline Retired & $1.85^{* *}$ & 0.59 & 0.63 & 0.77 & -0.02 & -0.10 \\
\hline Lincome & $1.85^{* *}$ & 0.59 & 0.63 & 0.77 & -0.02 & -0.10 \\
\hline Hukou & 0.93 & $0.67 *$ & -0.22 & 0.25 & 0.34 & $0.70 * * *$ \\
\hline \multicolumn{7}{|l|}{ Education } \\
\hline Junior & 0.23 & 0.03 & 1.43 & 0.30 & -0.25 & 0.56 \\
\hline Senior & 0.23 & 0.03 & 1.43 & 0.30 & -0.25 & 0.56 \\
\hline College or above & $1.21 *$ & 0.10 & 1.66 & -0.22 & 0.37 & 0.29 \\
\hline \multicolumn{7}{|l|}{ Homeownership } \\
\hline Relatives & -0.20 & -0.07 & -0.00 & -0.46 & 0.60 & 0.12 \\
\hline \multicolumn{7}{|l|}{ Respondent or } \\
\hline spouse & $-1.34 *$ & $-0.65^{*}$ & 0.65 & 0.20 & 0.47 & -0.08 \\
\hline Embeddedness & $1.01 * * *$ & $0.48^{* *}$ & 0.34 & 0.15 & $0.68 * * *$ & $0.51 * * *$ \\
\hline \multirow[t]{2}{*}{ Neighborliness } & 0.81 & 0.17 & 0.30 & 0.29 & 0.24 & 0.16 \\
\hline & & & & & & - \\
\hline Constant & $-5.29 *$ & $-4.21 * * *$ & $-6.09 *$ & $-5.31 * *$ & $-5.97 * * *$ & $4.72 * * *$ \\
\hline $\mathrm{N}$ & 463 & 463 & 309 & 309 & 871 & 871 \\
\hline AIC & 273.22 & 574.07 & 258.29 & 422.26 & 701.09 & 1103.47 \\
\hline
\end{tabular}

Notes: $* * * \mathrm{p}<0.001 ; * * \mathrm{p}<0.01 ; * \mathrm{p}<0.05$. As for homeownership, relatives and respondent or spouse stand for owned by relatives and owned by respondent or spouses respectively. As for types of community, danwei, commercial, villas and urban village stand for danwei compounds, ordinary commercial estate, villas or high-end neighborhoods, newly converted urban village respectively.

Table 4 presents the logit models by types of neighborhood. In model 3 and model 4 , it is shown that in danwei compounds, Party is negatively associated with the two kinds of community participation, which is in clear contrast with the overall pattern revealed in table 1. The scenarios in un-redeveloped old neighborhoods and ordinary commercial estates, however, are more consistent with the findings in full sample. In old un-redeveloped neighborhoods, Party members participate in volunteering significantly more active and insignificantly so in voting. In commercial estates, party members are significantly more active in both volunteering and voting (Figure3). Although the negative association in danwei compounds does not reach statistical significance, this finding lends credence to hypothesis 3, implying the distraction and squeezing effects of danwei context on Party members' community participation. Then, amid the transformation in which the urban governance unit changes from danwei to community and the identity of urbanites changes from danwei-person (danwei ren) to society-person (shehui ren), the danweis still have the upper hand in the competition with the RCs and Street Offices in captivating the civic as well as political energies of CCP members dwelling in danwei 
compounds. The RCs' mobilization of Party members is constrained by the RC staff's fellow state agents who are in the position of danwei employers.

The coefficients of other variables of interest in this subsample analysis are somewhat elusive, so we simply present the results themselves and note that because of the dwindled sample sizes, they should be interpreted with caution. A reference is Li's(2009) article, it finds that in the subsample of old residential neighborhoods (consisting of un-redeveloped old neighborhoods and danwei compounds), Party members are active participants in RC voting. But as model 2 and model 4 in Table 4 report, in these two types of 'old residential neighborhoods', Party membership's effects on RC voting are not statistically significant, and signs of coefficients are positive for one, negative for the other.

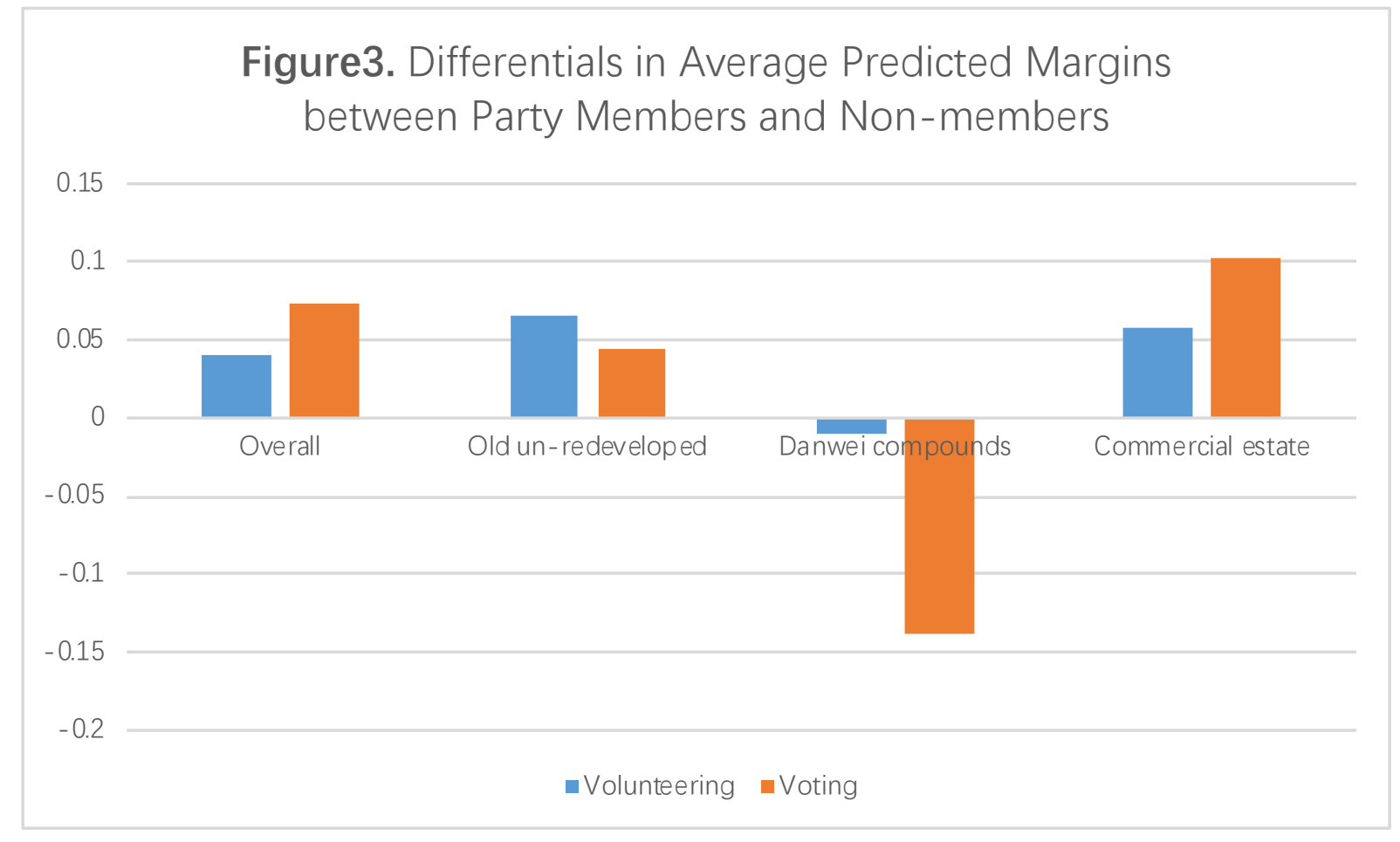

\section{Summary and discussion}

Drawing on nationally representative data, we have found that Party members are indeed important mobilization targets in the community building campaign which demand active participation on the part of community residents in volunteering services and RC elections. Serving as state-designated vanguards, Party members commit themselves more zealously to community-wide engagement than ordinary citizens, as expected by the Party-state. The fact that Party members are only more significantly likely to attend volunteering but not voting reveals the emphasis of grassroots mobilization. Party members are more focused on producing performance legitimacy and grassroots stability than on promoting democratization at the community level. By utilizing the involvement of party members and other ordinary residents to build a harmonious urban social space and take care of those who inhibit this space, the Party state may get to maintain its legitimacy based on moral performance (Zhao 2001). In this sense, regime stability might be strengthened without incurring much additional costs and without sustaining long-term economic growth. In general, what we find corroborates with 
Zhang(2017)'s research, implying that despite its declining ability to explicitly reward Party members with material and career advancement, the Party still gets what it wants by maneuvering various organizational and identity-based strategies.

Given the differentials between the general inclination of retired and employed residents to participate, the mobilization work targeting Party members manifests itself more saliently among the employed residents. Contrary to the anecdotal observation that 'retired party members' take on the major responsibility in communities, the mobilization work targeting party members is more efficient to the extent that the spontaneous participatory enthusiasm of retirees is reaped in subtle combination with susceptibility brought about by party membership. It seems that the grassroots mobilization of Party-state may go through various channels which are employed interchangeably and complementarily, party members are deliberately targeted only when residents are otherwise generally not inclined to participate. Indeed, being a Party member is but one way in which a resident can get involved in the affairs of his or her inhabited community. Aside from retirees, those who are intensively embedded are also a vital group. If anything, social embeddedness appears to matter more consistently across the participatory forms and neighborhood types than party membership. What is implied is that horizontal ties among neighbors are an undeniable driving force of communal life in urban China, awaiting utilization either by the grassroots state or by the residents themselves.

In addition, the competition between danwei-based and community-based urban governance structure is remarkable for its contribution to the reversed direction of Party membership's influence in danwei compounds. So to speak, the competition between 'socialist land masters' and municipal territorial power unfolds not only in the realm of land rights (Hsing 2012) but also in that of urbanites' participation, given that the RCs are located at the lowest echelon of municipal administrative hierarchy.

The mobilization of social actors to fulfill state's own ends is certainly neither nationally nor temporally unique. The agenda of self-governance in community building campaign in contemporary urban China bears resemblance to communitarianism, advanced liberal governmentality, and the Third Way programs in terms of mobilizing citizens to govern themselves, but the organizational presence of Party-state agents and their indispensable role in initiating participatory activities in the community make the Chinese case hard to fit in these models completely (Heberer and Göbel 2011, 7-8; Cho 2013, 98; Lin and Kuo 2013; Tomba 2014, 174-75; see Bray 2006; F. Xu 2008). The organizational channel to specifically target CCP members in community mobilization seems to be incompatible with the theoretical frameworks rooted in liberal democracies in fundamental ways. At first glance, the mobilized community participants also strike observers as successors of the activists enthusiastically dedicating themselves to the socialist construction in the pre-reform period of China(Walder 1986; Solomon 1969; Oi 1991). But there is one thing unequivocally distinguishes these two groups of people, Mao's activists are dependent on Party-state patrons in terms of material interests and career mobility whereas the contemporary participants are not ${ }^{1}$. Community participants, though more or less mobilized by agents of Party-state, are under no coercion or command to do so, regardless of the channel mobilization goes through. Still, what is presently happening in urban communities adopts practices and organizational forms from Maoist mass 
mobilizations(Perry 2007; He 2009), but the quotidian, sustained and depoliticized nature of activities like volunteering and voting deviates from the confrontational and eruptive manner of revolutionary mobilization.

It is the mixture and ambiguity that make the nature of community governance practices in China perplexing and make detailed empirical investigation of residents' participation especially needed. The way mobilization occurs certainly draws on multiple templates of operation, inheriting from the past as well as borrowing from the foreign. The retired and the socially embedded are active participants, mirroring the congruence with democratic nations. With the exception of those living in danwei compounds, Party members are liable to get mobilized too, reminding us of the tenacious, multifaceted and internally partitioned presence of China's Party-state.

The proposition that there is no retreat of Party-state but its restructuring, retrenchment or regrouping in its relation to grassroots society has evolved from a prediction(Shue 1990, 75, 152) to a well-established fact(Cho 2013, 116; Sigley 2006). Then how the grassroots state agents conduct 'the continuing capacity of the regime to mobilize its citizenry behind stateinitiated projects'(Perry 2007, 15) becomes an intriguing question and requires nuanced elucidation. In this article, we have shown the role assumed by the CCP's own members in the community building campaign whilst mindful of its differentiation across diverse social groups and neighborhood contexts. By sketching the targets, emphasis, channels and constraints of Party-state's grassroots mobilization in its quest of 'building communities', we have shed some light on how the state's initiatives are implemented, the micro-foundation of its legitimacy, and how its ends are served but also restricted. In brief, this article makes one step further in illuminating the way state engages society and consolidate its standing in contemporary China.

\section{Note}

1. A caveat is this autonomy enjoyed by residents within urban communities may not apply to the most disadvantaged and marginalized residents, such as recipients of minimum livelihood guarantee (dibao) and the unemployed. They are indeed materially dependent on the RCs but largely fall out of the scope of this study as they only constitute a small proportion of residents and even more so of Party members.

\section{References}

Appleton, Simon, John Knight, Lina Song, and Qingjie Xia. 2009. "The Economics of Communist Party Membership: The Curious Case of Rising Numbers and Wage Premium during China's Transition." Journal of Development Studies 45 (2): 256-75. doi:10.1080/00220380802264739.

Benewick, Robert, and Akio Takahara. 2002. "'Eight Grannies with Nine Teeth between Them: Community Construction in China." Journal of Chinese Political Science 7. 
Bi, Xiangyang, Jun Jin, Mingjie Ma, and Jiangsui He. 2010. "The Reach of Danwei Mobilization: An Analysis on Urban Residents' Charitable Giving to Project Hope." Sociological Studies, no. 6: 149-77.

Bian, Yanjie, Xiaoling Shu, and John R. Logan. 2001. "Communist Party Membership and Regime Dynamics in China.” Social Forces 79 (3): 805-41. doi:10.1353/sof.2001.0006. Bray, David. 2005. Social Space and Governance in Urban China:The Danwei System from Origins to Reform. Stanford: Stanford University Press.

_. 2006. "Building 'Community': New Strategies of Governance in Urban China." Economy and Society 35 (4): 530-49. doi:10.1080/03085140600960799.

Chen, Jie, and Chunlong Lu. 2007. "Social Capital in Urban China: Attitudinal and Behavioral Effects on Grassroots Self-Government." Social Science Quarterly 88 (2): 422-42.

Chen, Zhao, Ming Lu, and Yiqing Xu. 2015. "The Voice of Migrants: How Does Hukou Affect the Public Consciousness and Participation in China?" Chinese Journal of Sociology 1 (3): 447-68. doi:10.1177/2057150X15593719.

Cho, Mun Young. 2013. The Specter of “The People." Ithaca and London: Cornell University Press. doi:10.1017/CBO9781107415324.004.

Derleth, James, and Daniel R. Koldyk. 2004. "The Shequ Experiment: Grassroots Political Reform in Urban China." Journal of Contemporary China 13 (41): 747-77. doi:10.1080/1067056042000281404.

Dickson, Bruce J. 2014. "Who Wants to Be a Communist? Career Incentives and Mobilized Loyalty in China." The China Quarterly, no. 217(March): 42-68. doi:10.1017/S0305741013001434.

Erwin, Kathleen, Vincanne Adams, and Phuoc Le. 2009. "Glorious Deeds: Work Unit Blood Donation and Postsocialist Desires in Urban China.” Body \& Society 15 (2): 51-70. doi:10.1177/1357034X09103437.

Forrest, Ray, and Ngai-Ming Yip. 2007. "Neighbourhood and Neighbouring in Contemporary Guangzhou.” Journal of Contemporary China 16 (50): 47-64. doi:10.1080/10670560601026736.

Guan, Bing, and Yongshun Cai. 2015. "Interests and Political Participation in Urban China: The Case of Residents' Committee Elections." China Review 15 (1): 95-116.

Gui, Y., Joseph Y.S. Cheng, and Weihong Ma. 2006. "Cultivation of Grass-Roots Democracy: A Study of Direct Elections of Residents Committees in Shanghai." China Information 20 (1): 7-31. doi:10.1177/0920203X06062386.

Gui, Yong, Weihong Ma, and Klaus Mühlhahn. 2009. "Grassroots Transformation in Contemporary China." Journal of Contemporary Asia 39 (3): 400-423. doi:10.1080/00472330902944487.

Guo, Gang. 2007. "Organizational Involvement and Political Participation in China." Comparative Political Studies 40 (4): 457-82. doi:10.1177/0010414005285751.

He, Lichao. 2009. "Still the Age of the State? Organized Social Participation and Civil Society Development in Urban China." Pacific Focus 24 (3): 317-40. doi:10.1111/j.1976-5118.2009.01028.x. 
Heberer, Thomas, and Christian Göbel. 2011. The Politics of Community Building in Urban China. London and New York: Routledge. doi:10.4324/9780203828458.

Ho, Wing-Chung. 2010. The Transition Study of Postsocialist China: An Ethnographic Study of a Model Community. Singapore: World Scientific Publishing.

Hoffman, Lisa. 2013. "Decentralization as a Mode of Governing the Urban in China:

Reforms in Welfare Provisioning and the Rise of Volunteerism." Pacific Affairs 86 (4): 835-56. doi:http://dx.doi.org/10.5509/2013864835.

Hsing, You-tien. 2012. The Great Urban Transformation: Politics of Land and Property in China. Oxford: Oxford University Press.

Hu, Rong. 2008. "Social Capital and Political Participation of Urban Residents." Sociological Studies, no. 5: 142-59.

Li, Bobai, and Andrew G Walder. 2001. "Career Advancement as Party Patronage :

Administrative Elite , 1949 - 1996.” American Journal of Sociology 106 (5): 13711408 .

Li, Ding, and Chengzuo Tang. 2016. "Elite Grouping and Political Screening: Party Member Recruitment among College Students in Contemporary China." Open Times, no. 3: $158-75$.

Li, Hongbin, Lingsheng Meng, Qian Wang, and Li-An Zhou. 2008. "Political Connections, Financing and Firm Performance: Evidence from Chinese Private Firms." Journal of Development Economics 87 (2): 283-99. doi:10.1016/j.jdeveco.2007.03.001.

Li, Jun. 2009. "Home Ownership and Political Activism: Democratizing Neighborhood in Urban China." Sociological Studies 24 (5): 57-82.

Li, Jun, and Hongbo Wang. 2012. "Home Ownership and Political Participation in Urban

China." Chinese Sociological Review 44 (4): 58-81. doi:10.2753/CSA21620555440403.

Lin, W I, and C Kuo. 2013. "Community Governance and Pastorship in Shanghai: A Case Study of Luwan District." Urban Studies 50 (6): 1260-76.

doi:10.1177/0042098012465903.

Luova, Outi. 2011. "Community Volunteers' Associations in Contemporary Tianjin:

Multipurpose Partners of the Party-State.” Journal of Contemporary China 20 (72): 773-94. doi:10.1080/10670564.2011.604500.

Mccabe, Brian J. 2013. "Are Homeowners Better Citizens? Homeownership and Community Participation in the United States." Social Forces 91 (3): 929-54. doi:10.1093/sf/sos185. Ministry of Civil Affairs of PRC. 2016a. "Plan on Construction of Community Service System (2016-2020)."

http://www.mca.gov.cn/article/yw/jczqhsqjs/fgwj/201612/20161200002614.shtml.

—. 2016b. "Statistics Bulletin of Social Service Development (1996-2016)." http://www.mca.gov.cn/article/sj/tjgb/.

Office of the State Council. 2011. "Plan on Construction of Community Service System (2011-2015)." http://www.gov.cn/zwgk/2011-12/29/content_2032915.htm.

Oi, Jean. 1991. State and Peasant in Contemporary China: The Political Economy of Village Government. Oakland, California: University of California Press. 
Okun, Morris A, and Amy Schultz. 2003. "Age and Motives for Volunteering: Testing Hypotheses Derived from Socioemotional Selectivity Theory." Psychology and Aging 18 (2): 231-39. doi:10.1037/0882-7974.18.2.231.

Pan, Zhenfeng. 2004. "Housing Quality of Communist Party Members in Urban China: A Comparative Study." Housing Studies 19 (2): 193-205.

doi:10.1080/0267303032000168595.

Perry, Elizabeth J. 2007. "Studying Chinese Politics: Farewell to Revolution?” The China Journal, no. 57: 1-22.

Portes, Alejandro. 2000. "The Two Meanings of Social Capital.” Sociological Forum 15 (1): $1-12$.

Read, Benjamin L. 2012. Roots of the State: Neighborhood Organization and Social Networks in Beijing and Taipei. Redwood City: Stanford University Press.

Shi, Tianjian. 1997. Political Participation in Beijing. Cambridge: Harvard University Press. Shue, Vivienne. 1990. The Reach of the State: Sketches of the Chinese Body Politic.

Redwood City: Stanford University Press.

Sigley, Gary. 2006. "Chinese Governmentalities: Government, Governance and the Socialist Market Economy." Economy and Society 35 (4): 487-508. doi:10.1080/03085140600960773.

Solomon, Richard H. 1969. "On Activism and Activists : Maoist Conceptions of Motivation and Political Role Linking State to Society." The China Quarterly 39: 76-114. http://www.jstor.org/stable/652533.

Takahara, Akio, and Robert Benewick. 2006. "Party Work in the Urban Communities." In The Chinese Communist Party in Reform, edited by Kjeld Erik Brodsgaard and Zheng Yongnian, 157-72. London and New York: Routledge. http://ebooks.cambridge.org/ref/id/CBO9781107415324A009.

The Ministry of Civil Affairs. 2000. "The Opinions of the Ministry of Civil Affairs on Extending and Furthering Urban Community Construction." http://theory.people.com.cn/GB/40746/3491444.html.

Tomba, Luigi. 2014. The Government Next Door. Neighborhood Politics in Urban China. Ithaca: Cornell University Press.

Walder, Andrew G. 1986. Communist Neo-Traditionalism: Work and Authority in Chinese Industry. Berkeley: University of California Press. 1995. "Career Mobility and the Communist Political Order." American Sociological Review 60 (3): 309. doi:10.2307/2096416.

_ 2004. "The Party Elite and China's Trajectory of Change." China: An International Journal 2 (2): 189-209. doi:http://doi.org/10.1353/chn.2004.0015.

Walder, Andrew G., and Xiaobin He. 2014. "Public Housing into Private Assets: Wealth Creation in Urban China." Social Science Research 46. Elsevier Inc.: 85-99. doi:10.1016/j.ssresearch.2014.02.008.

Walder, Andrew G., Bobai Li, and Donald J. Treiman. 2000. "Politics and Life Chances in a State Socialist Regime: Dual Career Paths into the Urban Chinese Elite, 1949 to 1996." American Sociological Review 65 (2): 191. doi:10.2307/2657437. 
Wang, Fu-qin. 2016. "The Research of Community Heterogeneity and Chinese Citizens' Participation in Village (Neighborhood) Election." Tongji University Journal Social Science Section 27 (3): 60-69.

Xie, Guihua, and Yangyang Zhang. 2016. "Seeking out the Party: A Study of the CCP Membership Recruitment among Chinese College Students." Chinese Journal of Sociology (Chinese Version) 36 (3): 32-63. doi:10.15992/j.cnki.31-1123/c.2016.03.002.

Xiong, Yihan. 2008. "The Paradox of Urban Community Elections between Political Apathy and High Turnout Rates." Society 28 (3): 180-204.

Xu, Feng. 2008. "New Modes of Urban Governance: Building Community/ Shequ in PostDanwei China." In The Chinese Party-State in the 21st Century, edited by André Laliberté and Marc Lanteigne, 22-38. Oxon: Routledge. doi:10.4324/9780203933275.

$\mathrm{Xu}$, Qingwen, Douglas D. Perkins, and Julian Chun-Chung Chow. 2010. "Sense of Community, Neighboring, and Social Capital as Predictors of Local Political Participation in China." American Journal of Community Psychology 45 (3-4): 259-71. doi:10.1007/s10464-010-9312-2.

$\mathrm{Xu}$, Yongxiang. 2008. "Division of Tasks and Cooperation between Government and the Community: An Essential Condition for the Reform and Innovation of China's Community-building System." Social Sciences in China 29 (1): 142-51. doi:10.1080/02529200801930888.

Yang, Aiping, and Yanhong Yu. 2012. "Selective Pressurizing-Responding: An Organizational Study of the Behavior Logic of the Community Residents' Committee." Sociological Studies, no. 4: 105-26.

http://d.wanfangdata.com.cn/periodical_rkyj200506010.aspx.

Yang, Min. 2007. "Community as State Governance Unit:A Case Study on Residents' Community Participation and Cognition in the Process of Community Building Campaign." Sociological Studies, no. 4: 137-64.

Zavisca, Jane R., and Theodore P. Gerber. 2016. "The Socioeconomic, Demographic, and Political Effects of Housing in Comparative Perspective." Annual Review of Sociology 42 (1): 1-21. doi:10.1146/annurev-soc-081715-074333.

Zhang, Han. 2015. "Party Building in Urban Business Districts: Organizational Adaptation of the Chinese Communist Party." Journal of Contemporary China 24 (94): 644-64. doi:10.1080/10670564.2014.975957.

2017. "Who Serves the Party on the Ground? Grassroots Party Workers for China's Non-Public Sector of the Economy." Journal of Contemporary China 564 (October 2017). Routledge: 1-17. doi:10.1080/10670564.2018.1389022.

Zhao, Dingxin. 2001. "China's Prolonged Stability and Political Future: Same Political System, Different Policies and Methods." Journal of Contemporary China 10 (28): 42744. doi:10.1080/10670560120067126.

Zhou, Min, and Hanning Wang. 2016. "Participation In Anti-Japanese Demonstrations in China: Evdence From a Survey on Three Elite Universities in Beijing." Journal of East Asian Studies 16 (3): 391-413. doi:10.1017/jea.2016.21. 
Zhu, Y., and Q. Fu. 2016. "Deciphering the Civic Virtue of Communal Space: Neighborhood Attachment, Social Capital, and Neighborhood Participation in Urban China." Environment and Behavior, 1-31. doi:10.1177/0013916515627308. 